\title{
EUNIS 2013: Always connected, the Umea University campus and city network approach
}

\author{
Soren Berglund ${ }^{1}$ \\ ${ }^{1} \mathrm{ClO}$ Umea University, Sweden, soren.berglund@umu.se
}

\section{Keywords}

wireless, city, airport, bus station, railway station, eduroam.

\section{ABSTRACT}

This paper describes the current network approach at Umea University and how the strategy has changed over the years to meet new challenges. Today, we face two important scenarios that have to be managed within budget limitation and increased user demands.

- the rapid growth of mobile devices put pressure on the University Wireless Network, and the Mobile Internet for the PTT's to deliver accessibility.

- the expectation of users, students and staff to be connected all the time and everywhere, on campus, in the city, in cafes and stores, on buses, in airplanes and on trains with enough network performance to use the application they want.

Umea University has a large network, connected to Internet via the national university research network Sunet. The university has approx. 25,000 network outlets and 17,000 of them are active, the rest is a reserve for internal moving around. $100 \mathrm{Mbps}$ is standard for a personal workplace but can be upgraded to higher speed for servers and users with high demands. The wireless network has 520 access-points, all scattered sparsely around the campus for maximum coverage. There are three Wlans accessible all over the campus:

UmU Wlan - a closed network that can be accessed with your digital university identity, i.e. CAS or AD eduroam - the federated global university network

Adm - the federated network from the local community

The Umeå city open network (SSID: City of Umea) is only available at the Museum of Contemporary Art and Visual Culture.

In 2010, the university and the local community agreed to federate their wireless networks to make Internet available in community premises for students and staff. For the university, the major benefit is that students can access the university network from local libraries, schools and other local facilities around the city.

The university has an agreement with Telia, the major PTT, for both mobile telephones and mobile internet. The university has been moving on the road to Office Extension and offers staff to close their landline office telephones and move over to mobile telephony only. This approach builds on access to mobile telephony as the cell phone gradually takes over as the only office telephone extension for staffers. During 2013 , the +20 -year old university switchboard will be replaced by Lync 2013 which is a further extended approach to telecommunication. Office@365 and GoogleApps adds collaboration tools to the workplace and the concept Unified Communication is now being implemented and has currently $600+$ users in the first installation phase. 


\section{MORE AND MORE DEMANDS FOR INTERNET CONNECTIONS}

In autumn 2011, the Telecom department at the university began to receive complaints about accessibility of the network on cell telephones on the campus. Access to Mobile Internet was also weak. A lot of students and staff and the public in general had acquired mobile devices during the summer and the load on the Mobile Internet was increasing fast.

Next, complaints came from users of the Wlans:It was impossible to connect, connections suddenly vanished, slow speed, etc.

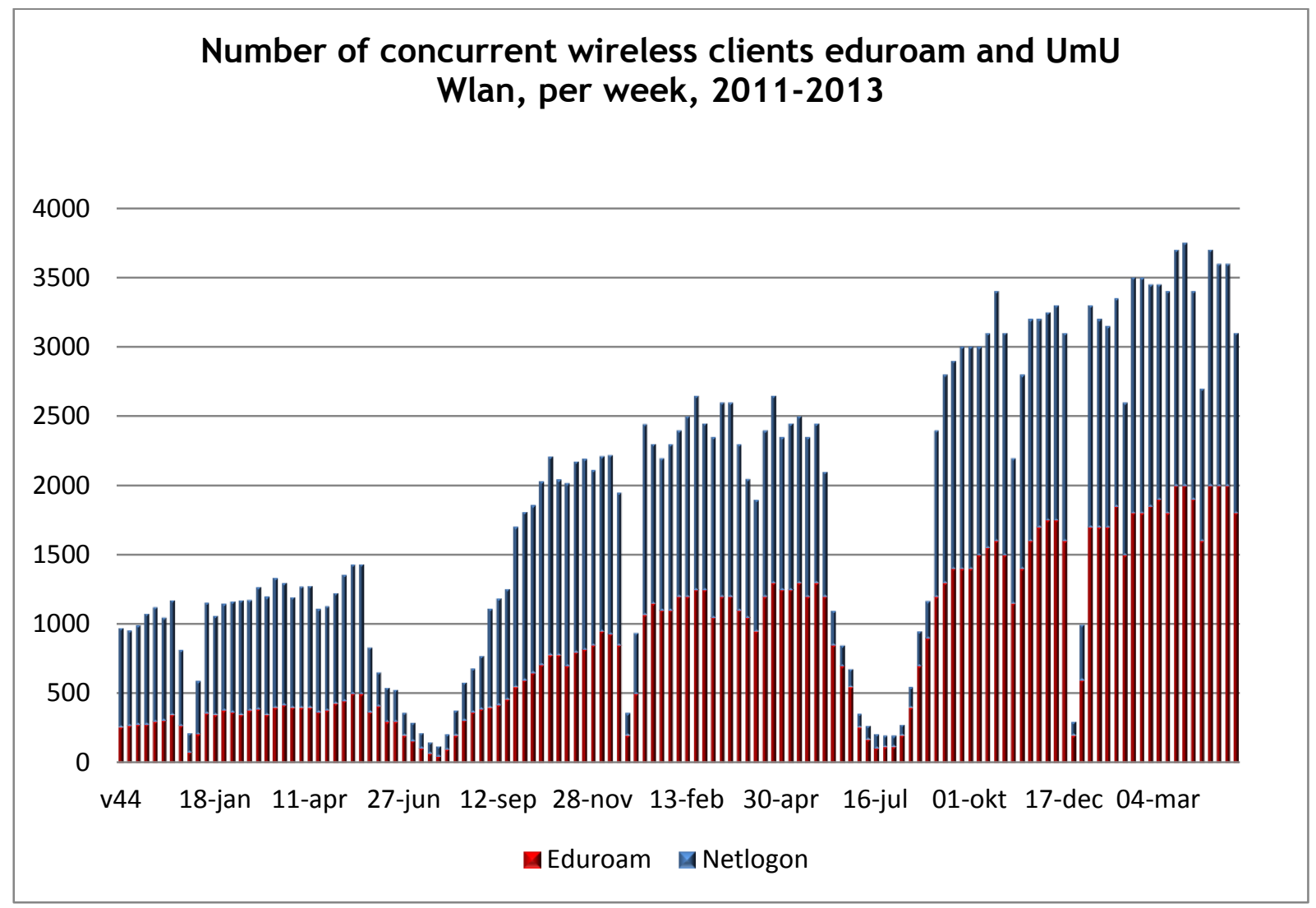

Fig.1. Increasing number of concurrent clients

The university network policy is - first you should use the wired network and then the Wireless as an addendum for visitors and students without a wired connection. This approach has worked well until autumn 2011 when we could see a lot more users trying to connect to the Wireless with their laptops, smartphones and tablet computers. This increase in demand for access shows no signs of reduced growth in the coming years. It is today common for a staff member to have a lot of internet connections up and running simultaneously:

- Fixed line network for laptop and stationary computers

- Wireless eduroam for the laptop - not closed when connected to dock station with fixed line

- Mobile Internet for the laptop

- Smartphone connection (Mobile Internet and eduroam)

- Tablet connection (Mobile Internet and eduroam)

We can anticipate this increase in the coming years and that puts pressure on our network and number of access points. We have a shortage of access points and if we do not do something about it really quickly, the verdict from students and staff will be tough. We need to reserve funding for a massive investment in access points, particularly where there are bunches of people on the campus. 


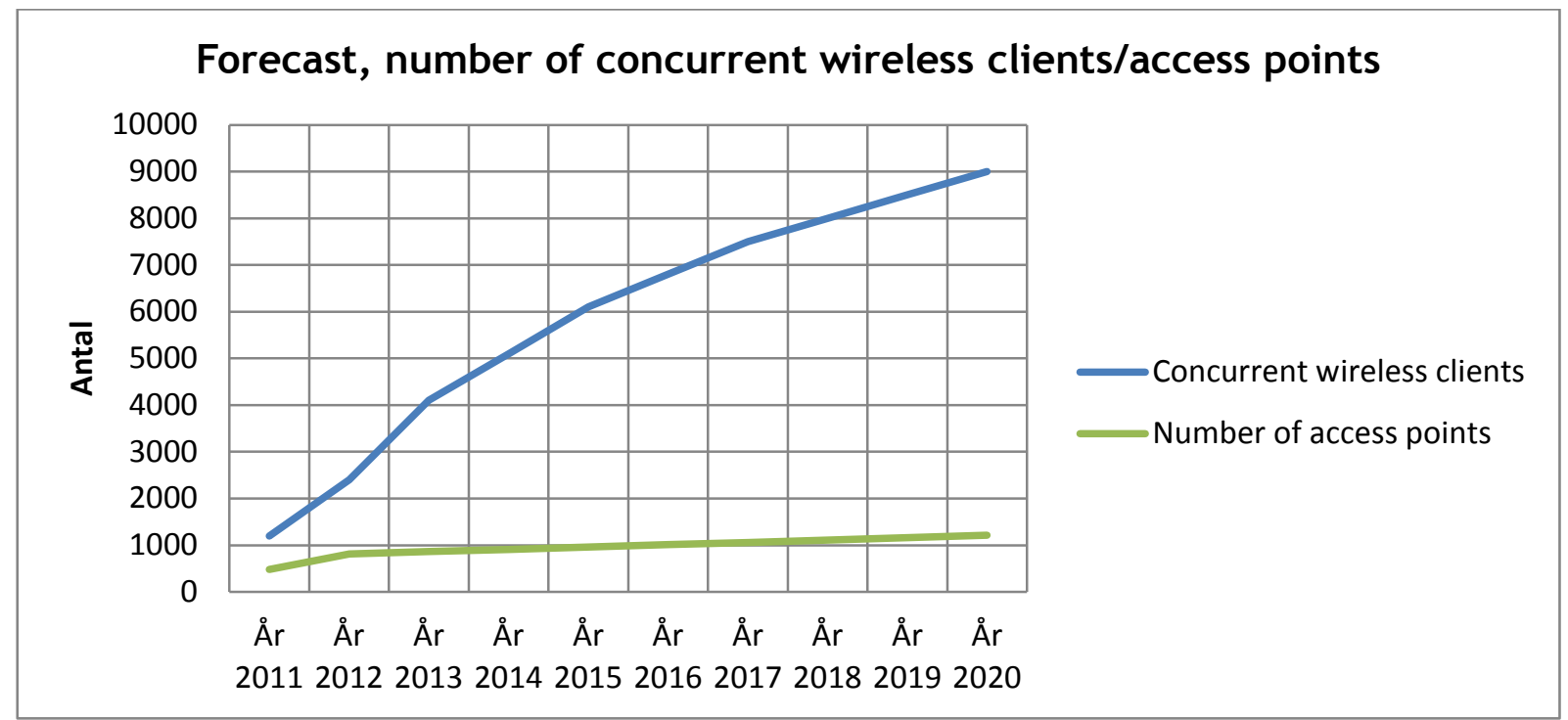

Fig.2. The gap between increasing numbers of concurrent users and access points

\section{CONNECTED EVERYWHERE}

For students and staff to be connected anywhere, the university and the local community moved on further from the federation described earlier into a plan to connect everybody, everywhere in the city. Priority is given to the airport, bus terminals and the railway station where students and staff spend time waiting. Also, the center of the city is connected with outdoor WiFi. This was possible due to collaboration with the local energy company, owned by the city, which has black fibers all over the city and the region, and a private company, The Cloud, that provides access in the airport and the railway stations. The local city bus operator, Ultra, has installed Internet in the buses, the railway has internet in the coaches and the airlines are installing internet in their airplanes.

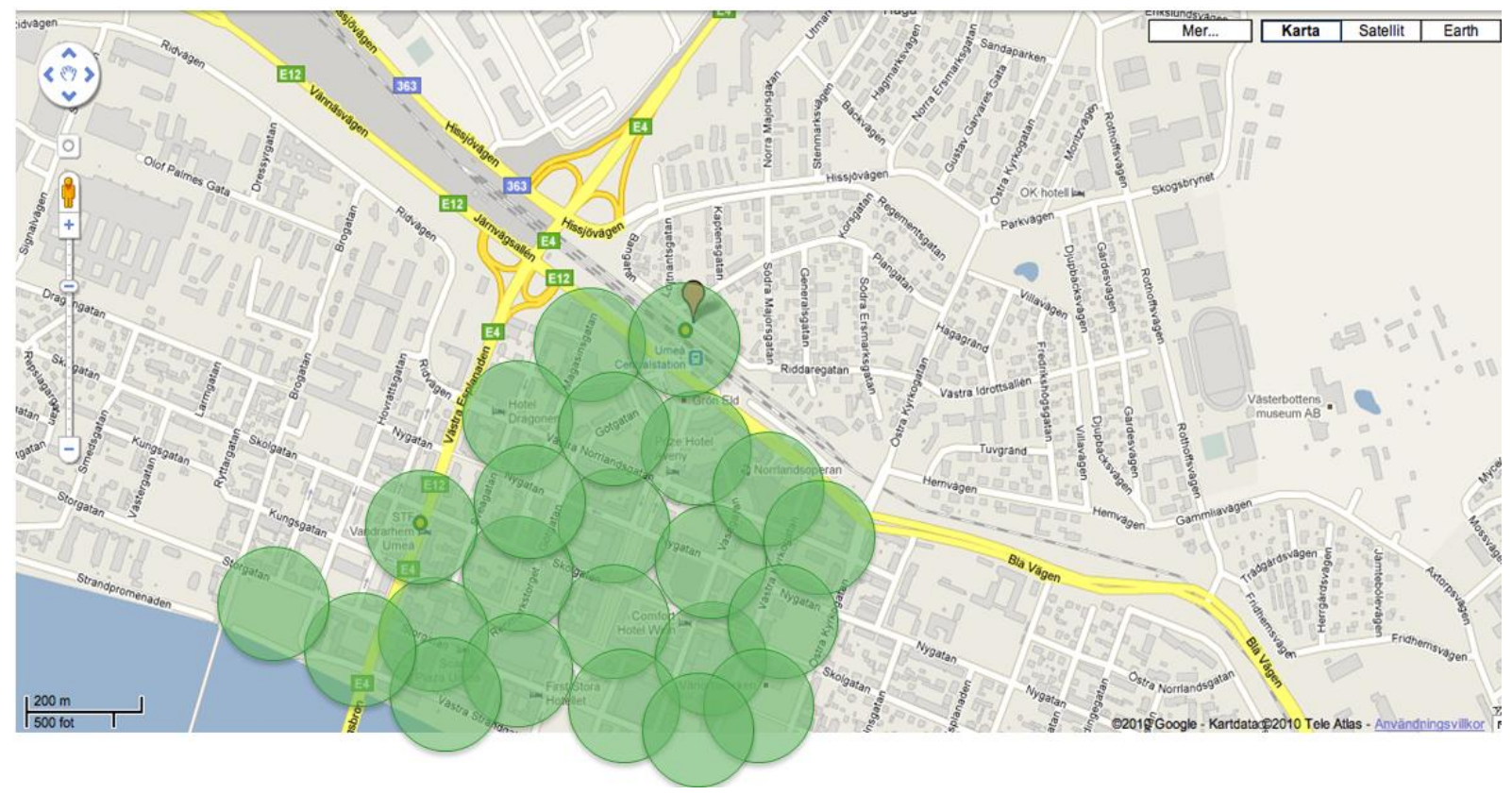

Fig.3. The outdoor hotspots in city center 
The local community offers an open network, primarily for visitors, with $15 \mathrm{~min}$ free Internet access. The user is routed to a landing page with information about the city. Next, you can access the Internet for free, but the short period only allows you to check your e-mail or do some quick surfing.

\section{Wireless City of Umea}

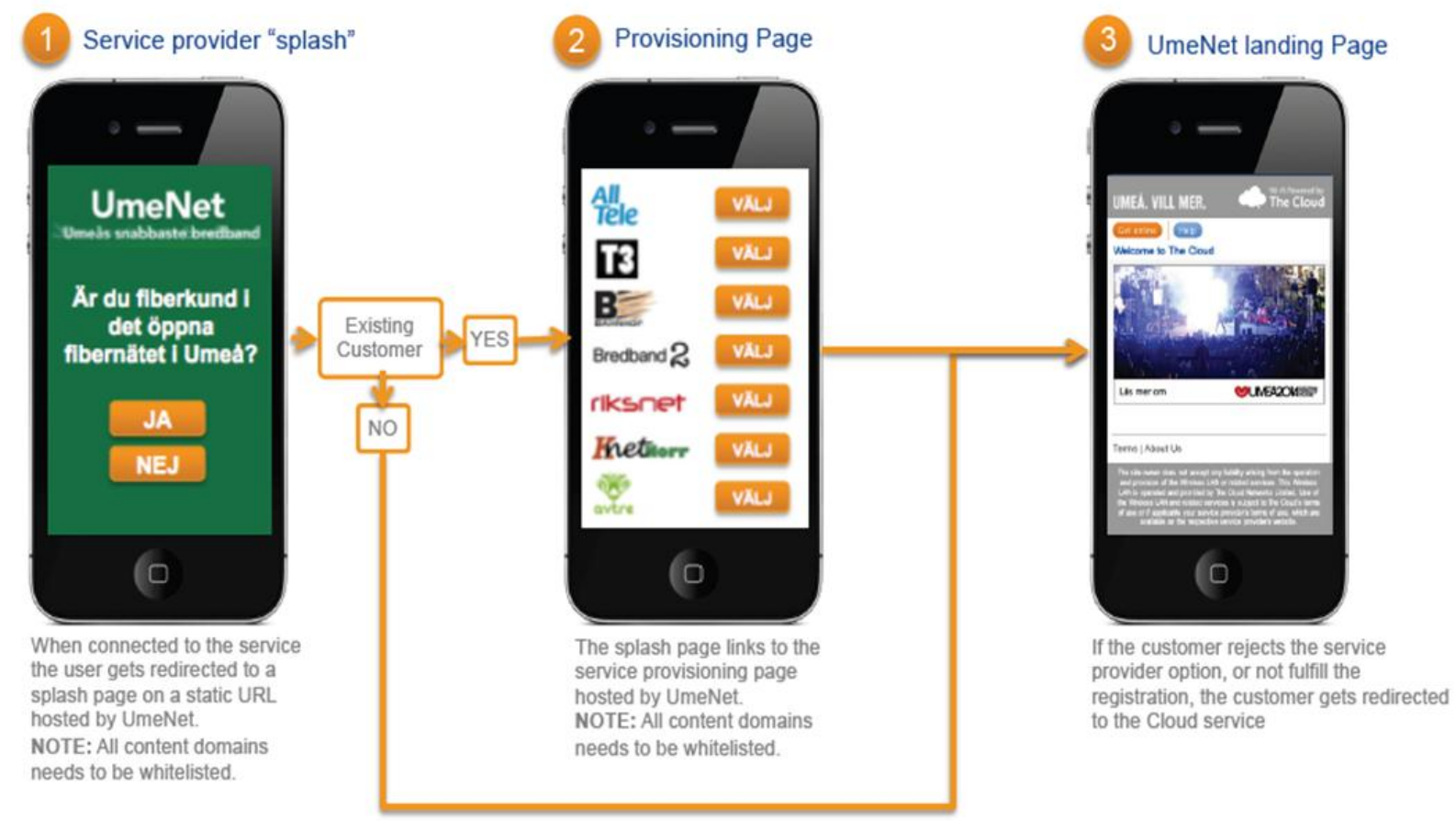

Fig.4. The wireless network in the city as seen in your cell phone

For students and staff eduroam is available with no limitation. Access to university resources is allowed when you login as a university user. Access is restricted if you access university resources from another network (use VPN if needed). This gives the university users an experience of university availability all around town and no login procedures since eduroam does an automatic login if available.

Our students at our remote campuses are to be included in this vision as well. The university has a campus in another city, Ornskoldsvik, approx. $100 \mathrm{~km}$ south of Umea. The campus hosts 1,000 students and 400 of them study courses at Umea University. A student is connected to the university in the campus premises and when travelling to Umea, the walking route from the local campus to the train station is covered by outdoor WiFi, the train station and the train has Internet connection and when arriving at the Umea south railway station, the station and the pathway to the main university campus is also covered.

\section{FINAL WORDS}

The vision of "always connected" for students and staff is on the move in Umea, one of the worlds most connected cities. (http://www.akamai.com/stateoftheinternet/) For me, as $\mathrm{ClO}$, it is important to deliver a reliable infrastructure with easy access and well-designed security measures for the intentional use. I do not know what students and researchers will design and construct in the future but openness and accessibility are some fundamentals for innovation in IT. 


\section{PARTNERS:}

Umeå university. http://www.umu.se/

Umeå kommun (local community). http://www.umea.se/

Umeå energy (network provider). http://www.umeaenergi.se/

The Cloud (internet provider). http://www.thecloud.net/

Sunet (national university network provider). http://www.sunet.se/English/Home.html

\section{AUTHORS' BIOGRAPHIES}

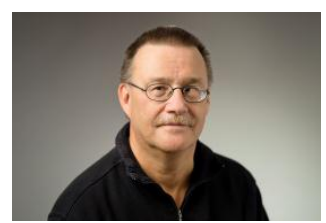

The author is the $\mathrm{ClO}$ for University of Umeå since 2009. He has a degree in Computer Science and Business, University of Umeå, 1978. After university studies, he was employed as System Analyst and Designer for business information systems. Returned to Umeå university for doctoral studies and teaching in Informatics with special focus in System Design and System Development. He has been a Project Manager for several national projects. He has been Head of the Ladok Division at the University of Umea, a large unit specialized in system development and maintenance. He has been a board member of EUNIS and worked as an expert for the European Commission. Related publications include:

Berglund, S (2011) Yes, I am a student. Give me a discount! The $17^{\text {th }}$ European University Information Systems Organisation (EUNIS) congress, EUNIS 2011. Dublin 15-17 June, 2011.

Lind, $M$ and Berglund, S (2008), e-Me - the Student's Best Friend. The 14th European University Information Systems Organisation (EUNIS) congress, EUNIS 2008 VISION IT - Visions for IT in Higher Education, University of Aarhus Universitet, Denmark (voted conference best paper) 